\title{
Saltmarsh vegetation and social environment influence flexible seasonal vigilance strategies for two sympatric migratory curlew species in adjacent coastal habitats
}

\author{
Jing Zhang ${ }^{1}$, Hang Zhang ${ }^{1}$, Yu Liu ${ }^{2}$, Huw Lloyd ${ }^{3}$, Jianqiang Li ${ }^{4}$, Zhengwang Zhang ${ }^{2}$ and Donglai Li ${ }^{*}$ (D)
}

\begin{abstract}
Background: Animals need to adjust their vigilance strategies when foraging between physically contrasting vegetated and non-vegetated habitats. Vegetated habitats may pose a greater risk for some if vegetation characteristics function as a visual obstruction but benefit others if they serve as protective shelter. Variation in group size, presence of similar species, along with variation in environmental conditions and anthropogenic disturbance can also influence vigilance investment.
\end{abstract}

Methods: In this study, we quantified the vigilance behaviour of two large-bodied, sympatric migratory curlew species_-Far Eastern Curlew (Numenius madagascariensis) and Eurasian Curlew (N. arquata) —in vegetated Suaeda salsa saltmarsh and non-vegetated mudflat habitat in Liaohekou National Nature Reserve, China. We used linear mixed models to examine the effects of habitat type, season, tide time, flock size (conspecific and heterospecific), and human disturbance on curlew vigilance investment.

Results: Both species spent a higher percentage of time under visual obstruction in S. salsa habitat compared to mudflat habitat but in response, only Far Eastern Curlew increased their percentage of vigilance time, indicating that visual obstruction in this habitat is only a concern for this species. There was no evidence that $\mathrm{S}$. salsa vegetation served as a form of cryptic background colouration since neither species decreased their vigilance effect in $\mathrm{S}$. salsa habitat in spring compared to the autumn migration season. The effect of curlew social environment (i.e. flock size) was habitat dependent since percentage of vigilance time by curlews in saltmarsh increased with both the number of individual curlews and number of other birds present, but not in mudflat habitat.

Conclusions: We conclude that both migratory curlew species exhibit a flexible vigilance adjustment strategy to cope with the different environmental and social conditions of adjacent and sharply contrasting coastal habitats, and that the trade-off between the risks of foraging and the abundance of prey may be a relatively common phenomenon in these and other shorebird populations.

Keywords: Flock size, Foraging behaviour, Linear mixed models, Numenius curlews, Suaeda salsa saltmarsh, Vigilance, Yellow Sea

\footnotetext{
*Correspondence: lidonglai@|nu.edu.cn

${ }^{1}$ Provincial Key Laboratory of Animal Resource and Epidemic

Disease Prevention, College of Life Sciences, Liaoning University, Shenyang 110036, China

Full list of author information is available at the end of the article
}

\section{Background}

Different kinds of vegetation can pose an inevitable selection pressure to foraging animals (Lantz et al. 2011). Vulnerable non-cryptic prey species can adapt by adjusting original author(s) and the source, provide a link to the Creative Commons licence, and indicate if changes were made. The images or other third party material in this article are included in the article's Creative Commons licence, unless indicated otherwise in a credit line to the material. If material is not included in the article's Creative Commons licence and your intended use is not permitted by statutory regulation or exceeds the permitted use, you will need to obtain permission directly from the copyright holder. To view a copy of this licence, visit http://creativecommons.org/licenses/by/4.0/. The Creative Commons Public Domain Dedication waiver (http://creativeco mmons.org/publicdomain/zero/1.0/) applies to the data made available in this article, unless otherwise stated in a credit line to the data. 
their behaviour to reduce their vulnerability from predators (Beauchamp 2015a), or take shelter provided by the vegetation (Cuthill et al. 2005; Stevens et al. 2011). Vigilance behaviour, a pause during foraging to scan the surrounding environment, is a well-known behavioural adaptation employed by animals to monitor potential threats from predators or competitors (Treves 2000; Beauchamp 2015a; Novčić 2020). Variation in vegetation characteristics can have a functional effect on an animal's vigilance, serving either as a form of "protection" by lowering the investment on vigilance behaviour, or as a "visual obstruction" requiring an increase in vigilance effort. The exact effect of vegetation on vigilance behaviour, however, may vary among different seasons when local environmental conditions change, or even vary between differently and sharply contrasting adjacent habitat types within the same landscape of the same season (Lazarus and Symonds 1992; Camp et al. 2012). Vigilance responses are also likely to differ between species, due to differences in their foraging ecology, dietary preferences, and prey availability (Li et al. 2017).

Annually, across the globe, millions of shorebirds concentrate on coastal intertidal mudflat landscapes to forage during their migratory season (Bamford et al. 2008; Bai et al. 2015; Wang et al. 2018; Kuang et al. 2020). At the cost of losing potential protective functions of vegetation, on the non-vegetated mudflats these birds can maintain a highly efficient anti-predator or anti-competitor vigilance by monitoring the environment without visual obstruction (Beauchamp 2014). At many shorebird stop-over sites, saltmarsh vegetation also forms a considerable landscape component adjacent to mudflats (Hao et al. 2017; Lu et al. 2018; Xing and Xing 2019) and attract large numbers of waterbirds foraging on abundant microbenthic and other prey species (Zhang et al. 2016, 2021; Li et al. 2020b). Compared to non-vegetated habitats, foraging in saltmarsh vegetation necessitates an adjustment to their vigilance strategy to cope with the potential visual obstruction of the vegetation structure, particularly when birds are "head down" (Metcalfe 1984; Li et al. 2017). These coastal intertidal mudflat landscapes thus represent a valuable opportunity to examine how birds adjust their vigilance in response to visual obstruction after shifting from non-vegetated mudflat to adjacent vegetated saltmarsh habitat.

During shorebird migration seasons, Suaeda salsa saltmarsh vegetation undergoes pronounced changes to its structural characteristics, varying from dense, lush, red vegetation in autumn to a more open (less dense), withered, tan-coloured vegetation in spring. Such seasonal variations in vegetation cover and quality may exert an influence on avian vigilance strategies while foraging in these habitats (Dreiss et al. 2011; Kjernsmo and Merilaita
2012; Medina et al. 2017). During spring migration, variegated tan-coloured saltmarsh vegetation may provide a cryptic background for many shorebirds that share a similar plumage colouration, potentially enabling them to reduce their investment in vigilance behaviour. Considering the decrease in the potential visual obstruction, shorebirds should exhibit a greater reduction in their vigilance during spring migration than during autumn.

Human disturbance and flock size are two additionally important social environmental factors that have significant influences on shorebird vigilance behaviour (Wang et al. 2011; Fuller et al. 2013; Murchison et al. 2016; Li et al. 2017; Linssen et al. 2019). Under disturbance regimes caused by fast-moving human activities, shorebirds will dramatically increase their vigilance or even move from such areas (Murchison et al. 2016). In contrast, under lower-level disturbance regimes, such as wildlife tourism, shorebirds may simply just modify their vigilance behaviour (Li et al. 2017). However, shorebird responses to both factors not only vary with different levels and types of human disturbance, but also flock species composition and levels of competition between flock members (Li et al. 2015; Cestari et al. 2020). On the one hand, birds can increase their vigilance in direct response to increasing competition between flock members (Beauchamp 2012). On the other hand, they could choose to reduce vigilance as a function of the "dilution" or "manyeyes" effects (Rieucau and Martin 2008; Beauchamp 2014). Some studies have confirmed that vigilance effort will decrease or increase as a function of increasing or decreasing flock size (Wang et al. 2011). Few studies have compared vigilance strategies between foraging sympatric congeneric species, which could greatly improve our understanding of how ecologically similar species adapt their vigilance strategy to foraging in sharply contrasting habitats within the same landscape.

The morphologically similar Far Eastern Curlew (Numenius madagascariensis, FEC) and Eurasian Curlew (N. arquata, EC) are two migratory shorebird species that are highly dependent on both $S$. salsa saltmarsh and mudflat habitat during their migration in the Yellow Sea region (Piersma 1985; Li et al. 2020a; Zhang et al. 2021). Although the global population of both sympatric species has declined in recent decades (Schwemmer et al. 2016; Pearce-Higgins et al. 2017), the Far Eastern Curlew population has declined more rapidly than its congener and is currently listed as Endangered by the IUCN (Studds et al. 2017; BirdLife International 2017a). The considerable difference in migratory distances undertaken by both species along the East Asian-Australasian Flyway (EAAF) (N. madagascariensis averaging $12,000 \mathrm{~km}$ vs. $5000 \mathrm{~km}$ for $N$. arquata orientalis) (Ueta et al. 2002; Driscoll and Ueta 
2002; Zhao et al. 2017; BirdLife International 2017b) implies species-specific energy-refueling requirements (Piersma 2007) with $N$. madagascariensis having a more limited foraging window (the increasing effort deserved to foraging will lower their effort on the vigilance) at stopover sites compared to its congener; a pattern typical of other congeneric shorebirds (Zhao et al. 2017; Si et al. 2018; Kuang et al. 2020).

In this study, we investigated how $S$. salsa saltmarsh vegetation and social environment (i.e. flock size) influence vigilance in these two sympatric curlews by comparing their vigilance behaviour when foraging in tidal mudflat and adjacent $S$. salsa saltmarsh vegetation during spring and autumn staging. We hypothesize that: (1) the vigilance effort of both species in $S$. salsa will be higher in saltmarsh vegetation than in mudflat habitat, particularly if the former habitat functions as a visual obstruction to foraging curlews on account of their head can be sheltered by $S$. salsa saltmarsh frequently; (2) both species will exhibit a greater degree of vigilance during autumn (when saltmarsh vegetation cover is greater) than in spring (when saltmarsh vegetation coloration may afford a degree of camouflage protection for both species); (3) both curlew species will increase their vigilant efforts under high levels of human disturbance and decrease vigilance with increasing flock size (both conspecific and heterospecific). In addition, we also examined the influence of time of day, tidal effects and distance of observers during data recording on curlew vigilance behaviour.

\section{Methods}

\section{Study site and species}

The present study was conducted during 2017-2019 in the estuarine wetland of the Liaohekou National Nature Reserve, Liaoning Province, China $\left(121^{\circ} 10^{\prime}-122^{\circ} 30^{\prime} \mathrm{E}\right.$, $\left.40^{\circ} 30^{\prime}-41^{\circ} 30^{\prime} \mathrm{N}\right)$. This nature reserve is widely known for the extensive $S$. salsa saltmarsh vegetation located on the supra-tidal zone above the intertidal mudflats around the estuarine delta (Fig. 1). The landscape of S. salsa vegetation and adjacent intertidal mudflats represents an important stopover habitat for many migratory shorebirds, including both curlew species (Zhang et al. 2021). We selected two large areas with adjacent $S$. salsa saltmarsh and mudflats on the west side of the reserve that are exposed to moderate levels of human disturbance related to oil production infrastructure. Further details about the study site are described in Li et al. (2020a) and Zhang et al. (2021). During autumn and spring migrations, approximately 700-1000 Far Eastern Curlews and 1250-1500 Eurasian Curlews are reported at the study site for approximately 2-3 months (Bai et al. 2015; Li Y. pers. communication) where they typically forage in loosely associated heterospecific flocks with species such as Bar-tailed Godwit (Limosa lapponica), and Great Knot (Calidris tenuirostris), or as solitary individuals ( $\mathrm{Li}$ et al. 2020a; Zhang et al. 2021).

\section{Behavioural observations}

We conducted behavioural observations of curlews during successive migratory stages (autumn: AugustOctober; spring: March-May) from 2017 to 2019. The

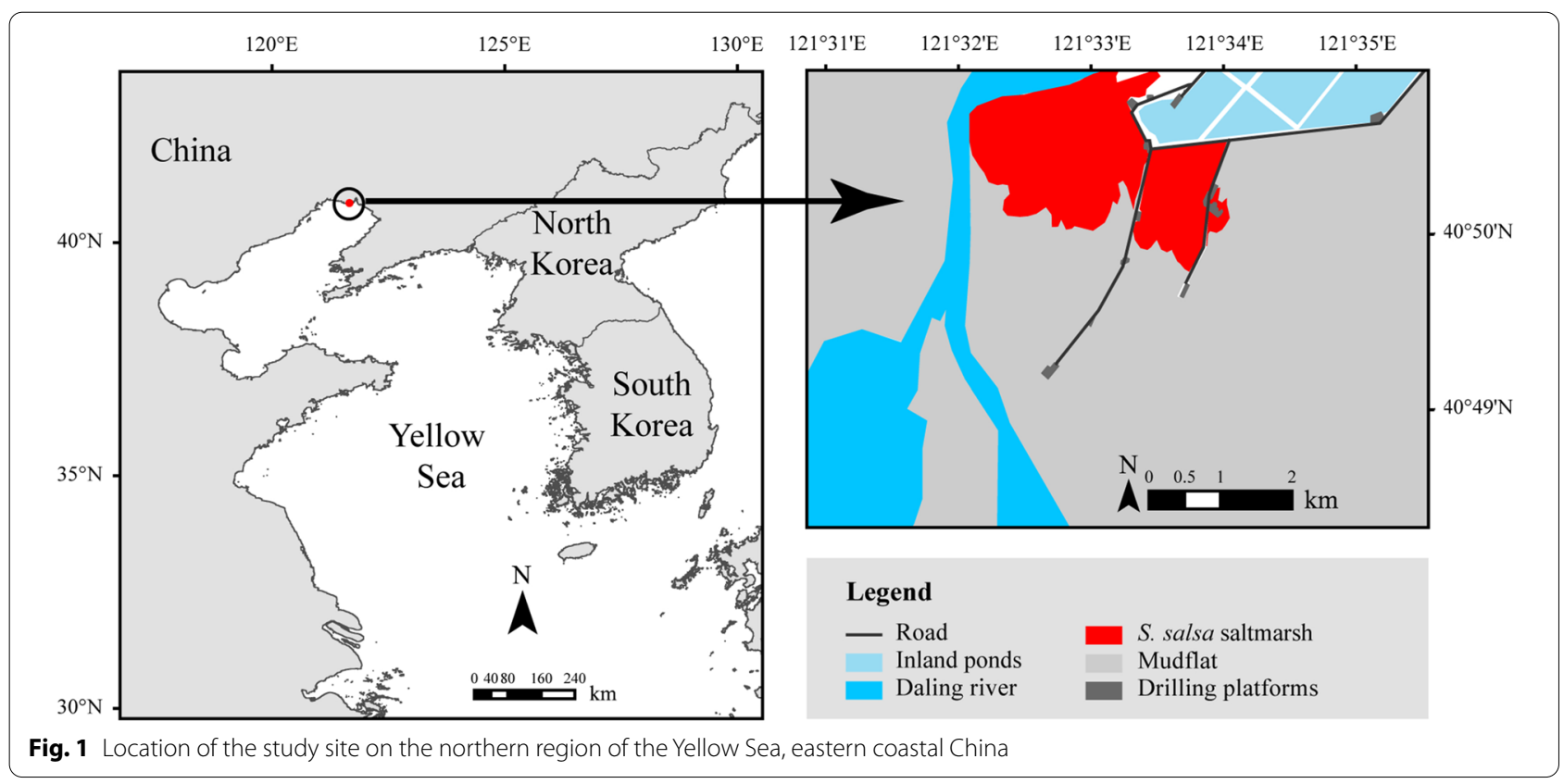


relatively large body size of Numenius species (average height: $50-60 \mathrm{~cm}$ ) relative to the height of the $S$. salsa vegetation (average height: $20-35 \mathrm{~cm}$ ) made it possible to assess curlew foraging and vigilance behaviour even when foraging with their heads positioned downward. We used digital cameras (NIKON P900S) to film curlew vigilance behaviour in the two habitats. Data recording was conducted on days of suitable weather (i.e. no heavy rain, snow or strong wind) and all recordings were made from semi-concealed vantage points on man-made structures (e.g. drilling platforms or dykes) to reduce any potential influence of the observer on curlews' behaviour. Each vantage point was separated by distances of 50-250 m, and the distance between observers and focal birds varied between 30 and $250 \mathrm{~m}$. On arrival at each vantage point, observers waited several minutes before recording curlew behaviour in order to reduce any potential disturbance to the birds caused by observers moving between points. Following this, one individual curlew was randomly selected, and its behaviour filmed for 10 min or until it moved out of the view. During each focal period, we recorded following variables: time of the day (morning: 8:00-11:00; midday: 11:00-14:00; afternoon: 14:00-17:00), observation distance, foraging habitat, absolute time to low tide, total number of individual curlews (combined total number of Far Eastern Curlew and Eurasian Curlews, but not including the focal individual), and total number of birds of other species within $10 \mathrm{~m}$ radius of the focal individual and presence/absence of human disturbance within $150 \mathrm{~m}$ of the focal individual. We used laser rangefinder (Bushnell SPORT 850) to measure the observation distance. Human disturbance included oil field production operations (e.g. traffic passing along the roads) and clam-harvesting activities by fishermen. At the end of each focal recording period, observers moved onto the next vantage point and repeated the behaviour recording protocol as described above. Although individual curlews were not banded or marked, the distance interval between observing points and period of recording represented an appropriate compromise between collecting adequate independent sample sizes whilst minimizing the risk of pseudo-replication (see also Li et al. 2020a).

\section{Video analysis}

Behavioural data were transcribed from video recordings by watching each video at half-normal speed using Baofeng player v.5.0 and Boris v.7.9.6. We only considered video samples $(n=298)$ that were longer than $5 \mathrm{~min}$ to increase sample size while minimizing potential errors associated with shorter observation lengths. We defined the vigilance behaviour of the curlews as consisting of an alert "head up" posture or scanning around while still standing. From each of these recordings, we extracted the duration time of each vigilance behaviour and total number of times of vigilance when the focal bird was foraging or walking. Moreover, in order to quantify the influence of visual obstruction on curlew's vigilance behaviour, we recorded the duration that the eyes of each focal curlew were obscured by $S$. salsa vegetation or by the mudflat surface whilst foraging in the tidal creeks from the video as an index of time spent sheltering (Li et al. 2017).

\section{Statistical analyses}

Differences in the percentage time of visual obstruction between habitats and species were assessed using independent $t$-tests or non-parametric Mann-Whitney $U$-tests when the data were not normally distributed. Linear mixed models (LMMs) were used to examine the effects of all fixed factors (species [Far Eastern Curlew, Eurasian Curlew], habitat [S. salsa saltmarsh, mudflat], human disturbance [yes, no], migration season [spring, autumn] and their two-way interaction) on the vigilance behaviour of both curlew species using R v.3.6.0 (CRAN; http://cran.r-project.org). Both dependent variables (frequency of vigilance [times $/ \mathrm{min}$ ] and percentage time spent on vigilance) and absolute time to low tide were lntransformed to normalize distribution before inclusion in the models (Pays and Jarman 2008). The number of individual curlews and the number of other birds within $10 \mathrm{~m}$ radius of the focal curlew were normalized by using a square root transformation separately before model construction.

Three LMMs were fitted by REML with the ln-transformed "percentage time spent on vigilance" and "frequency of vigilance, times/min" as response variables using the package lme4 (version 1.1-21; Bates et al. 2020). The global model included one random factor (Year), five categorical predictors: species (SP: FEC, EC), habitat type (HA: S. salsa saltmarsh, mudflat), human disturbance (HD: yes, no), migration season (MS: spring, autumn), time of the day (DT: morning, noon, afternoon) and five continuous covariates: observation distance (OD), number of individual curlews (CU: square-rooted transformed), number of other birds (OB: square-rooted transformed), absolute time to low tide (TT: ln-transformed) and the two-way interaction of habitat with other factors that was raised in the prediction. Variance inflation factor (VIF) analyses revealed no evidence of collinearity among variables ( $\mathrm{VIF}<2$ for all variables; Zuur et al. 2010).

We first ran global models and then $z$-score standardized all predictors using the standardize function in the package arm (Gelman et al. 2020). All candidate models were generated from global models using the dredge function in the package MuMIn v.1.43.6 (Barton 2020). 
We used Akaike's information criteria corrected for small sample sizes (AICc; Akaike 1973; Burnham and Anderson 2002) to assess model fit. All models were ranked using $\triangle \mathrm{AICc}$ and models with $\Delta \mathrm{AICc} \leq 2$ were considered as equivalent alternative models. Akaike weights $\left(w_{i}\right)$ were used to provide a quantitative measure of support for each model relative to the others (Burnham and Anderson 2002). Conditional model-averaged parameter values ( $\beta$-values) from all equivalent models were generated by the model averaging function in the MuMIn package. Wald test $z$-scores were examined to make inferences about each parameter estimate. Our initial ranking of models for vigilance frequency revealed only one model which satisfied the $\Delta \mathrm{AICc} \leq 2$ criteria, and as a result, only the top model was presented and selected without model averaged. Independent $t$-tests using Satterthwaite approximation (R Package: lmerTest v.3.1-0, Kuznetsova et al. 2020) were used to yield the statistical effect of each predictor of the selected model of "vigilance frequency". Post-hoc Tukey $t$-tests were used to compare within twoway interaction of fixed factors at the $P<0.05$ level statistical significance.

\section{Results}

During successive migration seasons, we recorded 298 focal observations of both species, corresponding to 2896 min of curlew behaviour. We obtained 173 behavioural observations of Far Eastern Curlew, which included 72 observations from saltmarsh habitat and 101 from mudflat habitat, compared to 125 observations of Eurasian Curlew, which included 57 observations from saltmarsh and 68 from mudflat habitat. Across the habitat, Far Eastern Curlews spent $8.1 \%$ and $4.5 \%$ of time on vigilance behaviour on the $S$. salsa saltmarsh and mudflat, respectively, compared to $7.13 \%$ and $6.6 \%$ by Eurasian Curlew.

\section{Habitat dependent visual obstruction, human disturbance and social environment}

Individual of both curlew species spent a significantly higher percentage of time under visual obstruction in the $S$. salsa saltmarsh compared with the adjacent mudflat in spring (FEC: $z=-3.77, P<0.001$; EC: $z=-5.32$, $P<0.001$ ) and autumn (FEC: $z=-7.15, P<0.001$; EC: $z=-5.01, P<0.001)$. The percentage time under visual obstruction in saltmarsh habitat was also significantly higher in autumn than in spring for both species (FEC: $t=-4.51, \mathrm{df}=69, P<0.001$, Fig. 2a; EC: $t=-2.54$, $\mathrm{df}=55, P=0.014$, Fig. 2b). In mudflat habitat, the time spent under visual obstruction by Far Eastern Curlew was significantly higher in autumn than spring $(z=-3.08$, $P=0.002)$ but differences between seasons for Eurasian Curlew were not significant $(z=-1.87, P=0.062)$. In addition, there were no significant difference in the frequency of sampling with human disturbance between S. salsa saltmarsh $(32.6 \%, n=129)$ and mudflat habitat (29.6\%, $\left.n=169 ; X^{2}=0.14, \mathrm{df}=1, P=0.705\right)$. However, both curlew species faced a higher percentage of disturbance from human activity in autumn $(46.9 \%, n=162)$ compared to spring $\left(11.8 \%, n=136 ; \chi^{2}=42.80, \mathrm{df}=1\right.$, $P<0.001)$. There was no significant difference in the number of individual curlews around the focal individuals between saltmarsh $(1.25 \pm 0.17, n=129)$ and mudflat habitats $(1.60 \pm 0.18, n=169 ; t=1.02, \mathrm{df}=296$,

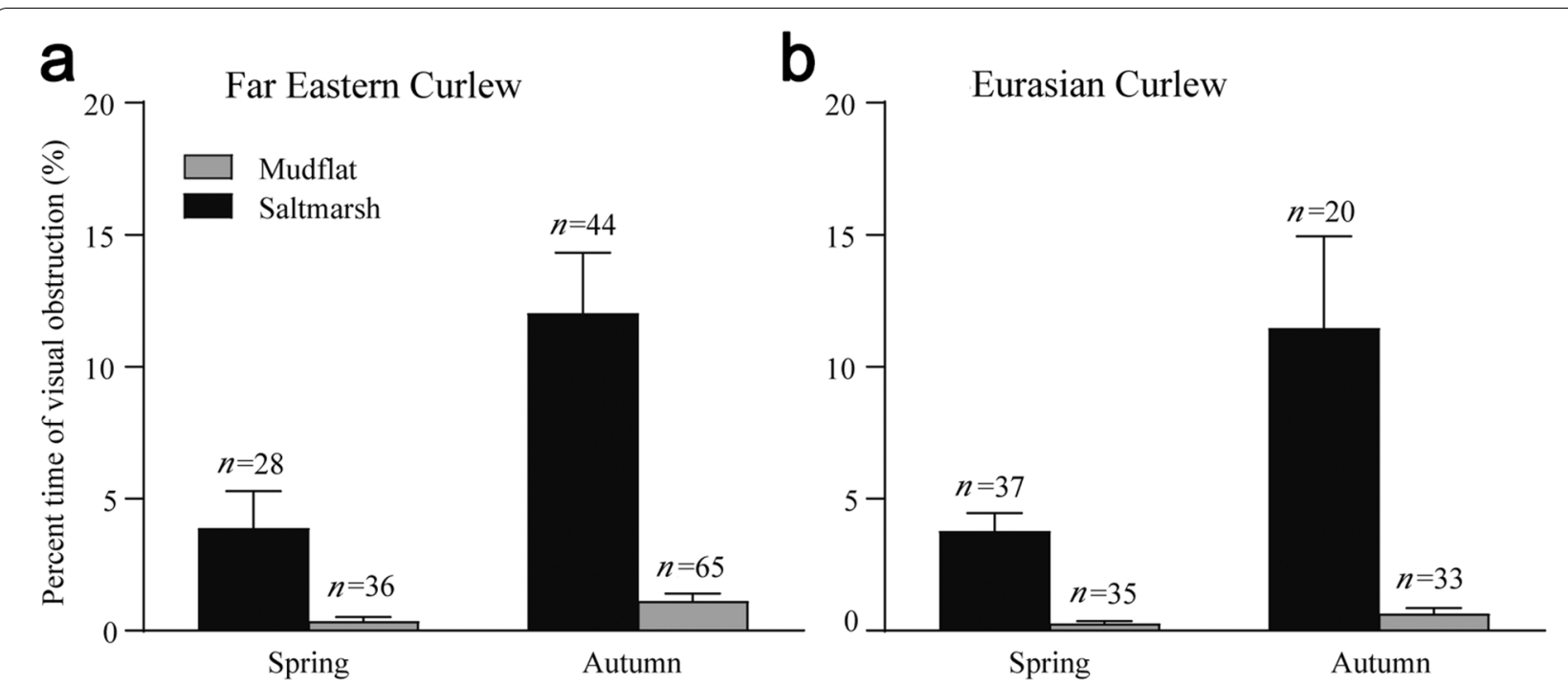

Fig. 2 Difference in the percentage time spent under visual obstruction \pm SE between Far Eastern Curlew (a) and Eurasian Curlew (b) in two different coastal habitats (S. salsa saltmarsh vs. mudflat) and seasons (spring vs. autumn) 
$P=0.308$ ), however, the number of other birds of heterospecific species around the focal curlews in saltmarsh $(1.98 \pm 0.29, n=129)$ was significantly lower than that in mudflat habitat $(7.91 \pm 1.48, n=169 ; t=4.84, \mathrm{df}=296$, $P<0.001)$.

\section{Predictors of percentage vigilance time in curlews}

We yielded nine subsets of candidate models that fitted the model selection criteria (Table 1). The conditional model-averaged parameter values $(\beta$-values) from all equivalent models, shown in Table 2 , revealed that there was no significant difference on the percentage of vigilance time between curlew species, but significant higher percentage of vigilance time in the saltmarsh than mudflat (Table 2). In addition, there was a significant interaction between species and habitats (Table 2). Specifically, Far Eastern Curlew exhibited a significantly higher percentage of vigilance time in $S$. salsa saltmarsh than in mudflat habitat $(t=3.90, P<0.001$; Fig. 3a), but not for Eurasian Curlew ( $t=0.12, P=0.919$; Fig. 3a). A significantly higher percentage of time spent on vigilance was found in spring than autumn (Table 2), particularly for the Eurasian Curlew $(t=4.50, P<0.001)$, but not for Far Eastern Curlew $(t=1.84, P=0.259$; Fig. 3b). There were no significant overall effects of number of individual curlews and number of other birds on the percentage of vigilance time, but significant interaction between habitat and number of individual curlews, and other birds (Table 2). Specifically, the percentage of vigilance time by curlews in saltmarsh increased both with number of individual curlews and number of other birds present within a $10 \mathrm{~m}$ radius of focal birds (Fig. 4), but not in mudflat habitat.
Table 2 Model-averaged coefficients of all candidate linear mixed models showing the response to percentage of vigilance time for both curlew species

\begin{tabular}{lcccr}
\hline Fixed effects & Estimate & SE & $\boldsymbol{z}$ value & $\boldsymbol{P}$ value \\
\hline (Intercept) & 1.68 & 0.35 & 4.79 & $<0.001$ \\
HA (SM) & 0.27 & 0.10 & 2.71 & 0.007 \\
MS (SP) & 0.47 & 0.12 & 3.97 & $<0.001$ \\
SP (FEC) & 0.01 & 0.10 & 0.12 & 0.906 \\
OB & -0.13 & 0.13 & 0.95 & 0.342 \\
HA (SM):SP (FEC) & 0.50 & 0.19 & 2.70 & 0.007 \\
HA (SM):OB & 0.72 & 0.28 & 2.57 & 0.010 \\
MS (SPR):SP (FEC) & -0.51 & 0.19 & 2.60 & 0.009 \\
CU & -0.12 & 0.11 & 1.17 & 0.243 \\
HA (SM):CU & 0.58 & 0.21 & 2.83 & 0.005 \\
HD (YES) & 0.21 & 0.12 & 1.76 & 0.079 \\
HD (YES):SP (FEC) & -0.45 & 0.22 & 2.05 & 0.040 \\
OD & -0.20 & 0.11 & 1.73 & 0.083 \\
\hline
\end{tabular}

The referenced categories for species, habitat, season and disturbance were "Eurasian Curlew: EC", "mudflat tideland: MF", "autumn: AU" and "no: NO", respectively. The abbreviations for spring, Far Eastern Curlews and saltmarsh are SPR, FEC, SM. Other abbreviations for the predicting factors refer to Table 1. Significant values are highlighted in italics

In addition, there was a significant interaction between human disturbance and curlew species (Table 2), with significantly higher percentage of vigilance time for the Eurasian Curlew $(t=2.64, P=0.04)$ under human disturbance, but not for the Far Eastern Curlew $(t=0.24$, $P=0.905$; Fig. $3 b$ ). Absolute time to low tide and time of the day were not significantly associated with the percentage of vigilance time for either species $(P>0.09$ for all other fixed effects; Table 2).

Table 1 Candidate linear mixed models with the response (percentage of vigilance time) as the dependent variable

\begin{tabular}{|c|c|c|c|c|c|c|}
\hline Response variables & Models & df & logLik & AICc & Delta AICc & AlCc weight \\
\hline \multirow[t]{9}{*}{ Percentage of vigilance time } & $\mathrm{HA}+\mathrm{MS}+\mathrm{SP}+\mathrm{OB}+\mathrm{HA}: \mathrm{SP}+\mathrm{HA}: \mathrm{OB}+\mathrm{MS}: \mathrm{SP}$ & 10 & -347.1 & 714.97 & 0 & 0.2 \\
\hline & $\mathrm{HA}+\mathrm{MS}+\mathrm{OB}+\mathrm{HA}: \mathrm{OB}$ & 7 & -350.63 & 715.65 & 0.68 & 0.14 \\
\hline & $\mathrm{HA}+\mathrm{MS}+\mathrm{SP}+\mathrm{CU}+\mathrm{OB}+\mathrm{HA}: \mathrm{CU}+\mathrm{HA}: \mathrm{SP}+\mathrm{HA}: \mathrm{OB}+\mathrm{MS}: \mathrm{SP}$ & 12 & -345.34 & 715.77 & 0.8 & 0.13 \\
\hline & $\mathrm{HD}+\mathrm{HA}+\mathrm{MS}+\mathrm{SP}+\mathrm{OB}+\mathrm{HD}: \mathrm{SP}+\mathrm{HA}: \mathrm{SP}+\mathrm{HA}: \mathrm{OB}+\mathrm{MS}: \mathrm{SP}$ & 12 & -345.49 & 716.07 & 1.1 & 0.11 \\
\hline & $\mathrm{HA}+\mathrm{MS}+\mathrm{CU}+\mathrm{HA}: \mathrm{OB}$ & 7 & -350.92 & 716.23 & 1.27 & 0.1 \\
\hline & $\mathrm{HA}+\mathrm{MS}+\mathrm{SP}+\mathrm{OD}+\mathrm{OB}+\mathrm{HA}: \mathrm{SP}+\mathrm{HA}: \mathrm{OB}+\mathrm{MS}: \mathrm{SP}$ & 11 & -346.87 & 716.67 & 1.7 & 0.08 \\
\hline & $\mathrm{HA}+\mathrm{MS}+\mathrm{CU}+\mathrm{OB}+\mathrm{HA}: \mathrm{CU}$ & 8 & -350.16 & 716.82 & 1.85 & 0.08 \\
\hline & $\mathrm{HA}+\mathrm{MS}+\mathrm{SP}+\mathrm{CU}+\mathrm{HA}: \mathrm{SP}+\mathrm{MS}: \mathrm{SP}$ & 10 & -348.03 & 716.83 & 1.86 & 0.08 \\
\hline & $\mathrm{HD}+\mathrm{HA}+\mathrm{MS}+\mathrm{SP}+\mathrm{OB}+\mathrm{HA}: \mathrm{SP}+\mathrm{HA}: \mathrm{OB}+\mathrm{MS}: \mathrm{SP}$ & 11 & -346.99 & 716.9 & 1.94 & 0.07 \\
\hline \multirow[t]{2}{*}{ Frequency of vigilance } & $M S+O B+M S: S P$ & 5 & -95.96 & 202.13 & 0 & 0.89 \\
\hline & $\mathrm{MS}+\mathrm{OB}+\mathrm{DT}$ & 6 & -96.96 & 206.21 & 4.09 & 0.11 \\
\hline
\end{tabular}

The models were chosen from among successive candidate models based on $\triangle \mathrm{AIC} \leq 2$ and ranked based on Akaike weights $\left(w_{i}\right)$. The abbreviations for each predicting factors as follow: species (SP), habitat type (HA), human disturbance (HD), migration season (MS), observation distance (OD), number of individual curlews (CU), number of other birds (OB), absolute time to low tide (TT), time of the day (DT) 


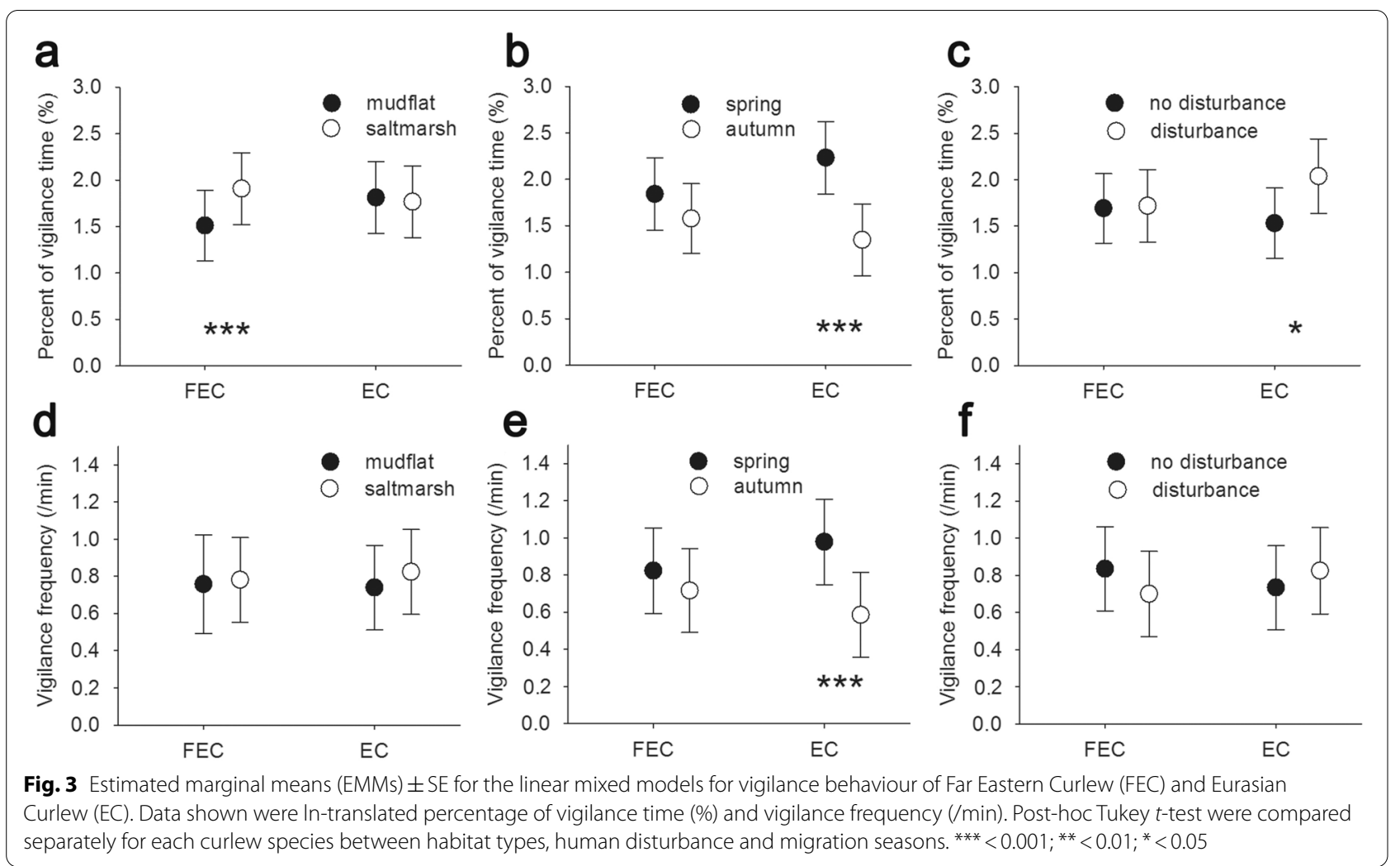

\section{Predictors of curlew vigilance frequency}

Only one model included the migration season, number of other birds and the interaction between migration season and curlew species were yielded during the model selection for the vigilance frequency (Table 1). There was a significantly higher vigilance frequency in spring than in autumn $(t=5.50, P<0.001$; Table 3$)$, particular for Eurasian Curlew ( $t=5.67, P<0.001$; Fig. 3e). Vigilance frequency of curlews also declined with the number of other birds (Table 3). No other predictors (i.e. habitat, human disturbance, number of individual curlews) had any significant effects on the model output (Figs. 3d, f, 4c).

\section{Discussion}

Our study reveals that both curlew species spent more time under visual obstruction in saltmarsh vegetation compared to mudflats (Fig. 2). S. salsa vegetation also exerts a significant effect on the percentage time of vigilance investment (although no significant increase in vigilance frequency) for curlews foraging in this habitat, particular for Far Eastern Curlews (Fig. 3a; Table 2). This result does lend strong support for our first hypothesis that $S$. salsa saltmarsh can function as a visual obstruction for this species. Contrary to our second hypothesis however, both forms of vigilance investment (percentage of time and frequency) were higher in spring than in autumn, especially for Eurasian Curlews (Fig. 3b, e; Table 1). Unlike their breeding environment (Thomas and Alexander 1996; Stevens et al. 2011) and the wintering mudflat habitat of Far Eastern Curlew, the tan-coloured saltmarsh vegetation appears not to afford a degree of cryptic background coloration for either species. In turn, seasonal variations in food supply and the energy requirement of birds may also influence vigilance behaviour. The relatively higher curlew vigilance in spring can be partly attributed to the variation in foraging and vigilance on different stages of the migratory journey, i.e. curlews are much further from their wintering grounds than to their breeding grounds during stopover in the Yellow Sea, and need to spend more time foraging whilst reducing vigilance.

Our study has revealed that both migratory curlew species exhibit a flexible vigilance adjustment strategy to cope with the different environmental conditions of adjacent coastal habitats. In this region of coastal China, saltmarsh habitat is used extensively by Far Eastern Curlew due to the abundance of its preferred mudflat crab (Helice tientsinensis) prey (Li et al. 2020a). Nonetheless, foraging in saltmarsh habitat may represent a more risky strategy for this globally threatened species since the vegetation can function as a visual obstruction for foraging birds, as has been noted for 

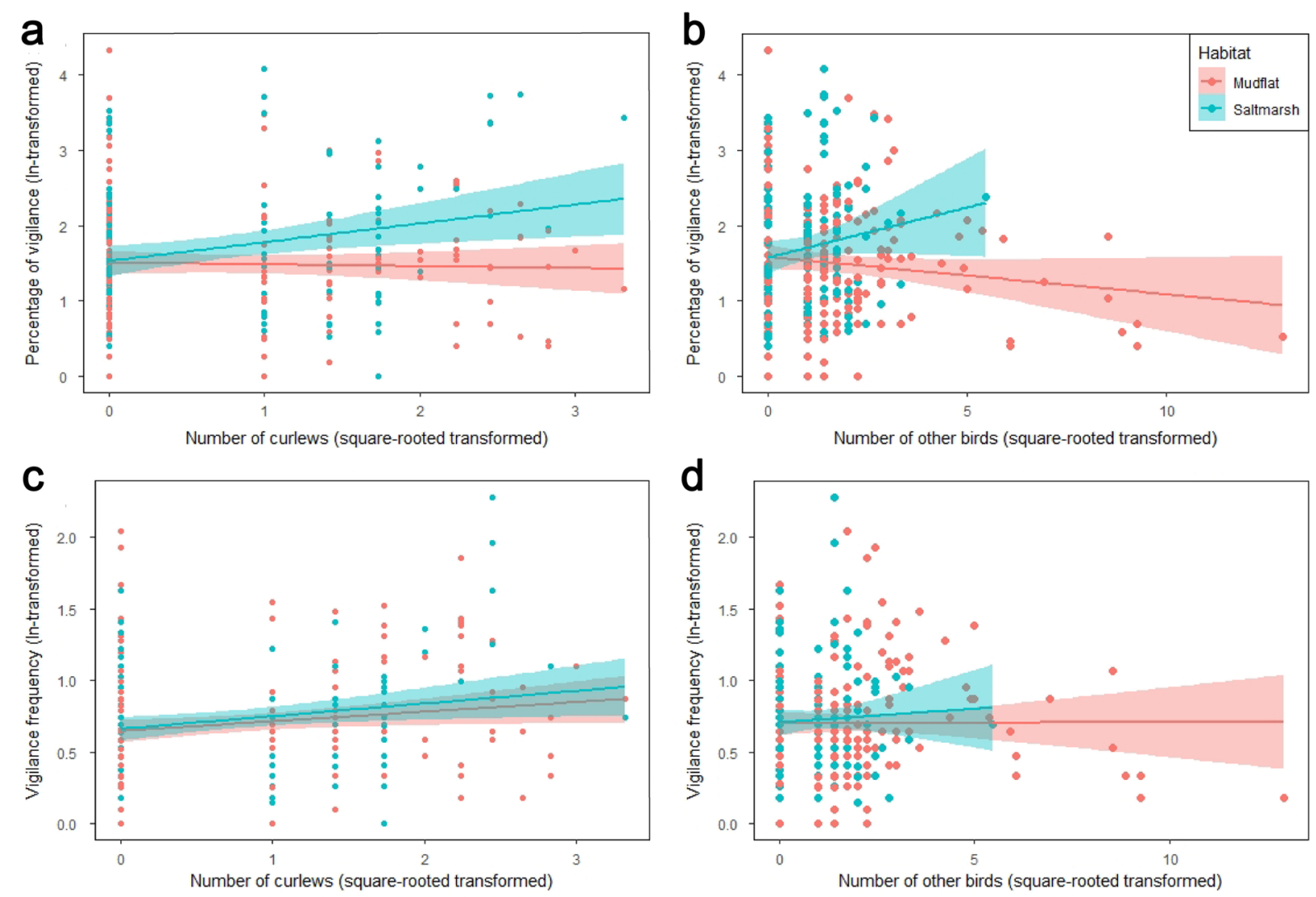

Fig. 4 Habitat-dependent variation in flock size (conspecific and heterospecific) and curlew vigilance behaviour (percentage of vigilance time, \% and vigilance frequency/min) in S. salsa saltmarsh and adjacent mudflat

Table 3 Estimated regression parameters, standard errors, $t$ values and $P$ values for each predictor variable to investigate the effects of habitat and social environment on the vigilance frequency of two curlew species

\begin{tabular}{lcccr}
\hline Fixed effects & Estimate & SE & $\boldsymbol{t}$ value & $\boldsymbol{P}$ value \\
\hline (Intercept) & 0.76 & 0.22 & 3.37 & 0.076 \\
MS (SPR) & 0.24 & 0.04 & 5.50 & $<0.001$ \\
OB & -0.06 & 0.01 & -4.48 & $<0.001$ \\
MS (AU):SP (FEC) & 0.14 & 0.06 & 2.44 & 0.015 \\
MS (SPR):SP (FEC) & -0.07 & 0.05 & -1.23 & 0.222 \\
\hline
\end{tabular}

Only two predictors (migration season and number of other birds) were included in the top model, which was the only model fitting the delta $\mathrm{AICc}<2$. The referenced categories for species and season are "Eurasian Curlew: EC" and "autumn: $A U$ ", respectively. The abbreviations for spring and Far Eastern Curlew are SPR and FEC. Significant values are highlighted in italics

Semipalmated Sandpiper (Calidris pusilla), Redcrowned Crane (Grus japonensis) and other waterbird species (e.g. Beauchamp 2015b; Li et al. 2017). This type of trade-off, between the risks of foraging and the abundance of prey, may therefore be a relatively common phenomenon for shorebirds (McNamara and Houston 1992; Ale and Brown 2007), with some empirical studies confirming that adjustments to vigilance behaviour can reduce predation risk of foraging birds (e.g. Dingemanse and Wolf 2013; Li et al. 2015). Furthermore, the functional effect exerted by vegetation was only apparent when assessing vigilance time but not vigilance frequency, suggesting that Far Eastern Curlews spend more time on monitoring potential threats per individual vigilance bout. This differs from our previously published work on Red-crowned Cranes (see Li et al. 2017) which increase their vigilance frequency but not vigilance time when individuals are completely obstructed from potential threats whilst foraging in Phragmites australis habitat. The difference in vigilance behaviour between curlews and cranes therefore relates to the level of obstruction caused by the relative height of vegetation to the focal bird. The mean height of S. salsa $(20-35 \mathrm{~cm})$ is lower than the height of either curlew species $(50-60 \mathrm{~cm})$ (Zhang et al. 2021), suggesting that the vegetation only obstructs the birds during head-down foraging. 
We acknowledge that increased vigilance investment by curlews in the $S$. salsa saltmarshes can also be attributed to their spatial proximity to woodland or manmade structures (e.g. electrical lines) that are utilized by numerous diurnal raptor species known to be predators of shorebirds foraging in the coastal zone. We have observed a small number of cases of curlew predation by Hen Harrier (Circus cyaneus) and Peregrine Falcon (Falco peregrinus). However, the mixed effect of spatial variation of predation risk and visual obstruction on curlew vigilance were largely difficult to unlock here and we encourage further experimental fieldwork to resolve this question.

It is important to remember that vigilance investment varies with foraging behaviour, for example, curlew vigilance would be expected to decrease when food density or availability increases, especially during stopover when increasing fat reserves is the priority for migrating individuals. However, we found that there was a higher density of tidal crabs during the autumn stopover but with much lower vigilance investment, and at our study site, the effect of crab availability, rather than density on vigilance seems to have been more important. However, the availability of crabs for other threatened migrants such as Red-crowned Cranes (Grus japonensis) is largely determined by burrowing ambient temperature which varies depending on time of day and season (Li et al. 2020b) and future studies should consider the influence of ambient temperature on curlew vigilance through its effects on prey availability.

Differences in vigilance strategies could also be partially explained by differences in handling time on different prey. Our previous study from the same location demonstrated that Eurasian Curlew shows a greater preference for ragworms (Nereis multignatha) in saltmarsh than in mudflat habitat, whereas Far Eastern Curlew tends to specialize on tidal crabs (see Li et al. 2020a). Handling times of ragworm prey should also be much shorter than handling times for crabs, which may allow Eurasian Curlews to spend a greater amount of time and more frequently scan both vegetated and non-vegetated habitats.

Habitat-dependent vigilance effort can also be partially explained by responses to changes in curlew social environment i.e. flock size in response to differences in prey abundance and prey mobility. At our study site, we found that vigilance increased with conspecific or heterospecific presence in saltmarsh but not in mudflat habitat. In general the presence of other birds serves as competitors especially for mobile prey that can hide easily in burrows, thus increasing the need for monitoring neighbouring individuals. In saltmarsh habitat, both curlew species tend to forage either in loose monotypic flocks or as solitary individuals on highly mobile and surface active crabs (Li et al. 2020a). However, in mudflat habitat they also forage with mixed-species flocks with different bird species separating ecologically along prey resource gradients including a higher density and greater porpotion of less mobile prey such as bivalves (Zhang et al. 2016; Feng et al. 2019), leading to reduced vigilance responses by curlews in mudflat habitat. Alternatively, they may benefit from a "risk-dilution" (Foster and Treherne 1981) or "many-eyes" effect (Rieucau and Martin 2008), which may explain why both vigilance variables were negatively related to the flock size of heterospecific birds. Other studies have also found that large heterospecific shorebird flocks can increase foraging rates of birds by decreasing vigilance investment and intraspecific competition at the same time (Fuller et al. 2013; Cestari et al. 2020).

Surprisingly, we found that Far Eastern Curlew showed a greater tolerance to human disturbance with lower vigilance efforts compared to Eurasian Curlew. This contrasts with our previous study in which the feeding rates on tidal mudflat crabs was significantly negatively influenced by forms of human disturbance (see Li et al. 2020a). Elsewhere on its wintering grounds in Australia, Far Eastern Curlews are often displaced by the presence of birds and domestic dogs if they approach within $100 \mathrm{~m}$ of individuals. Several studies have identified a degree of tolerance by Eurasian Curlew populations to some forms of human disturbance (e.g. Pfister et al. 1992; Wang et al. 2011; Pearse et al. 2017). On the other hand, the noticeable difference in the two curlews' vigilance under the same, non-lethal low levels of human disturbance means they have flexible vigilance strategy and/or perceive the types of human disturbance in this study as low-level threats. Given the degree of oil production infrastructure and the rapid development of tourism in the region (Ma et al. 2013; Hua et al. 2015; Tian et al. 2017; Lu et al. 2018), identifying and quantifying the influence of higherlevel forms of disturbance on shorebirds needs further research. In addition, we found that observation distance and time to absolute tide did not influence curlew vigilance behaviour. This suggests that our vantage point survey method, in which observers recorded curlews from semi-concealed vantage points on man-made structures (e.g. drilling platforms or dykes) was good at reducing the observer effect. The fact that absolute time to low tide on the vigilance efforts might suggest that prey availability was not tidal-dependent.

\section{Conclusions}

In conclusion, our study demonstrates that comparative studies of the effects of habitat type, season, flock size and human disturbance on vigilance behaviour can 
reveal the degree of behavioural plasticity among closely related, sympatric species. We show that at one stop-over site in the Yellow Sea region, S. salsa saltmarsh habitat can act as a significant visual obstruction for foraging migratory Far Eastern Curlews but this habitat does not afford a degree of cryptic background colouration for either curlew species during their spring migration stopover. Curlew social environment (i.e. flock size) can exert a significant effect on curlew vigilance whilst foraging. Moreover, the considerable differences in vigilance under the same levels of non-lethal human disturbance suggest that the two congeneric species exhibit a flexible vigilance strategy across adjacent coastal habitats; however, considering the dramatically decrease of Far Eastern Curlew population, conservation plans such as establishing a designated Ramsar protected area, reducing land reclamation, mitigating against potential impacts of oil production infrastructure in the tidal flat and promoting wildlife-based tourism are necessary (Hua et al. 2015; Tian et al. 2017; Lu et al. 2018). Whether these patterns are typical of either species at other stop-over sites within the EAAF, or across multiple coastal wetland habitat types within the same landscape mosaic, should be the focus of future studies.

\section{Acknowledgements}

We thank Ziqiang Huang, Yu Bai, Yanyan Liu, Jun Kong for their assistance with data collection in the field and Ayesha Zulfiqar, Ali Abid for their grammar review about the manuscript. We also thank two anonymous referees for their constructive comments.

\section{Authors' contributions}

$\mathrm{DL}, J \mathrm{~L}, \mathrm{ZZ}$ conceived and designed experiment. JZ, DL and $\mathrm{HZ}$ performed experiment. JZ, YL and DL analysed data. JZ and DL wrote the manuscript. JZ, $Y L, H L, Z Z, D L$ modified, edited and finalised the manuscript. All authors read and approved the final manuscript.

\section{Funding}

This work was financially supported by National Key Research and Development Program of China (No. 2017 YFC 1403500 to JL), National Natural Science Foundation of China (No. 31911540468 and 31672316 to DL), non-profit Foundation of Marine Environment and Ecological Conservation of CNOOC (CF-MEEC/TR/2020-20 to ZZ) and Natural Science Foundation of Liaoning Province of China (2019-MS-154 to DL).

\section{Availability of data and materials}

The datasets used in the present study are available from the corresponding author on reasonable request.

\section{Ethics approval and consent to participate}

This study was permitted by the Liaohekou National Nature Reserve Management Bureau (issued bu Yuxiang Li), and the experiments were executed with the current law of China, where the study was performed.

\section{Consent for publication}

Not applicable.

\section{Competing interests}

The authors declare that they have no competing interests.

\section{Author details}

${ }_{1}^{1}$ Provincial Key Laboratory of Animal Resource and Epidemic Disease Prevention, College of Life Sciences, Liaoning University, Shenyang 110036, China.
${ }^{2}$ Ministry of Education Key Laboratory for Biodiversity Science and Ecological Engineering, College of Life Sciences, Beijing Normal University, Beijing 100875, China. ${ }^{3}$ Ecology and Environment Research Centre, Department of Natural Sciences, Manchester Metropolitan University, Chester Street, Manchester M1 5GD, UK. ${ }^{4}$ School of Ecology and Nature Conservation, Beijing Forestry University, Beijing 100083, China.

Received: 31 January 2021 Accepted: 6 July 2021

Published online: 18 July 2021

\section{References}

Akaike $\mathrm{H}$. Information theory and an extension of the maximum likelihood principle. In: Petran BN, Csáki F, editors. Proceedings of the second international symposiumon on the information theory. Budapest: Akademiai Kiado; 1973. pp 267-81.

Ale SB, Brown JS. The contingencies of group size and vigilance. Evol Ecol Res. 2007;9:1263-76.

Bai QQ, Chen JZ, Chen ZH, Dong GT, Dong JT, et al. Identification of coastal wetlands of international importance for waterbirds: a review of China Coastal Waterbird Surveys 2005-2013. Avian Res. 2015;6:12.

Bamford M, Watkins D, Bancroft W, Tischler G, Wahl J. Migratory shorebirds of the East Asian-Australasian flyway: population estimates and internationally important sites. Canberra: Wetlands International-Oceania; 2008.

Bates D, Maechler M, Bolker B, Walker S, Christensen RHB, Singmann H, et al. Package Ime4: linear mixed-effects models using "Eigen" and S4. 2020. https://CRAN.R-project.org/package=Ime4.

Beauchamp G. Flock size and density influence speed of escape waves in semipalmated sandpipers. Anim Behav. 2012;83:1125-9.

Beauchamp G. Antipredator vigilance decreases with food density in staging flocks of Semipalmated Sandpipers (Calidris pusilla). Can J Zool. 2014:92:785-8.

Beauchamp G. Animal vigilance: monitoring predators and competitors. Oxford, UK: Academic Press; 2015a.

Beauchamp G. Visual obstruction and vigilance: a natural experiment. J Avian Biol. 2015b;46:476-81.

BirdLife International. Numenius madagascariensis (amended version of 2016 assessment). The IUCN Red List of Threatened Species 2017a: e.T22693199A118601473. 2017a. https://doi.org/10.2305/IUCN.UK.20173.RLTS.T22693199A118601473.en. Accessed 25 Dec 2020.

BirdLife International. Numenius arquata. The IUCN Red List of Threatened Species 2017:e.T22693190A117917038. 2017b. https://doi.org/10.2305/IUCN. UK.2017-3.RLTS.T22693190A117917038.en. Accessed 25 Dec 2020.

Burnham KP, Anderson DR. Model selection and multimodel inference. In: A practical information-theoretic approach. 2nd edn. NewYork: Springer; 2002.

Camp MJ, Rachlow JL, Woods BA, Johnson TR, Shipley LA. When to run and when to hide: the influence of concealment, visibility, and proximity to refugia on perceptions of risk. Ethology. 2012;118:1010-7.

Cestari C, da Silva Gonçalves C, de Melo C. Keeping safe and fed: large heterospecific shorebird flocks to decrease intraspecific competition. J Avian Biol. 2020;51:e02316.

Cuthill IC, Stevens M, Sheppard J, Maddocks T, Párraga CA, Troscianko TS, et al. Disruptive coloration and background pattern matching. Nature. 2005:434:72-4.

Dingemanse NJ, Wolf M. Between-individual differences in behavioural plasticity within populations: causes and consequences. Anim Behav. 2013;85:1031-9.

Dreiss AN, Antoniazza S, Burri R, Fumagalli L, Sonnay C, Frey C, et al. Local adaptation and matching habitat choice in female barn owls with respect to melanic coloration. J Evol Biol. 2011;25:103-14.

Driscoll PV, Ueta M. The migration route and behaviour of Eastern Curlews Numenius madagascariensis. Ibis. 2002;144:E119-30.

Feng CC, Zhang SD, Liu WL, Zhao TT, Cao YD, Xiang-Yu JG, et al. Food composition of five migratory shorebirds at the Dandong Yalu River coastal wetland in spring migration. J Fudan Univ (Nat Sci). 2019;58:497-505 (in Chinese).

Foster WA, Treherne JE. Evidence for the dilution effect in the selfish herd from fish predation on a marine insect. Nature. 1981;293:466-7. 
Fuller RA, Bearhop S, Metcalfe NB, Piersma T. The effect of group size on vigilance in Ruddy Turnstones Arenaria interpres varies with foraging habitat. Ibis. 2013;155:246-57.

Gelman A, Su YS, Yajima M, Hill J, Pittau MG, Kerman J, et al. arm: data analysis using regression and multilevel/hierarchical models. $R$ package version 1.11-2. 2020. https://CRAN.R-project.org/package=arm.

Hao XL, Deng L, He Y. An analysis of dynamic monitoring and landscape pattern change of Suaeda salsa wetlands in Panjin using remote sensing technology. Wetland Sci Manage. 2017;13:31-6 (in Chinese).

Hua N, Tan K, Chen Y, Ma ZJ. Key research issues concerning the conservation of migratory shorebirds in the Yellow Sea region. Bird Conserv Int 2015;25:38-52.

Kjernsmo K, Merilaita S. Background choice as an anti-predator strategy: the roles of background matching and visual complexity in the habitat choice of the least killifish. Proc R Soc B. 2012;279:4192-8.

Kuang F, Coleman JT, Hassell CJ, Leung K-SK, Maglio G, Ke W, et al. Seasonal and population differences in migration of Whimbrels in the East AsianAustralasian Flyway. Avian Res. 2020;11:24

Kuznetsova A, Brockhoff PB, Christensen RHB, Jensen SP. ImerTest: tests in linear mixed effects models. 2020. https://CRAN.R-project.org/package= ImerTest.

Lantz SM, Gawlik DE, Cook MI. The effects of water depth and emergent vegetation on foraging success and habitat selection of wading birds in the Everglades. Waterbirds. 2011;34:439-47.

Lazarus J, Symonds M. Contrasting effects of protective and obstructive cover on avian vigilance. Anim Behav. 1992;43:519-21.

Li C, Zhou L, Xu L, Zhao NN, Beauchamp G. Vigilance and activity time-budget adjustments of wintering hooded cranes, Grus Monacha, in humandominated foraging habitats. PLoS ONE. 2015;10:e0118928.

Li DL, Liu Y, Sun X, Lloyd H, Zhu S, Zhang S, et al. Habitat-dependent changes in vigilance behaviour of Red-crowned Crane influenced by wildlife tourism. Sci Rep. 2017;7:16614.

Li DL, Zhang J, Liu Y, Lloyd H, Pagani-Núñez E, Zhang ZZ. Differences in dietary specialization, habitat use and susceptibility to human disturbance influence feeding rates and resource partitioning between two migratory Numenius curlew species. Estuar Coast Shelf Sci. 2020a;245:106990.

Li DL, Zhang J, Chen LY, Lloyd H, Zhang ZZ. Burrow ambient temperature influences Helice crab activity and availability for migratory Red-crowned cranes Grus japonensis. Ecol Evol. 2020b;10:11523-34.

Linssen $\mathrm{H}$, van de Pol M, Allen AM, Jans M, Ens BJ, Krijgsveld KL, et al. Disturbance increases high tide travel distance of a roosting shorebird but only marginally affects daily energy expenditure. Avian Res. 2019;10:31.

Lu WZ, Xiao JF, Lei W, Du JQ, Li ZJ, Cong PF, et al. Human activities accelerated the degradation of saline seepweed red beaches by amplifying topdown and bottom-up forces. Ecosphere. 2018;9:e02352.

Ma ZJ, Cheng YX, Wang JY, Fu XH. The rapid development of birdwatching in mainland China: a new force for bird study and conservation. Bird Conserv Int. 2013;23:259-69.

McNamara JM, Houston Al. Evolutionarily stable levels of vigilance as a function of group size. Anim Behav. 1992;43:641-58.

Medina I, Delhey K, Peters A, Cain KE, Hall ML, Mulder RA, et al. Habitat structure is linked to the evolution of plumage colour in female, but not male, fairy-wrens. BMC Evol Biol. 2017;17:35.

Metcalfe NB. The effects of habitat on the vigilance of shorebirds: is visibility important? Anim Behav. 1984;32:981-5.

Murchison CR, Zharikov Y, Nol E. Human activity and habitat characteristics influence shorebird habitat use and behavior at a Vancouver Island migratory stopover site. Environ Manage. 2016;58:386-98.

Novčić I. Underwater foraging increases the incidence of head-up position in dunlin (Calidris alpina). Acta Ethol. 2020;23:115-8.
Pays O, Jarman PJ. Does sex affect both individual and collective vigilance in social mammalian herbivores: the case of the eastern grey kangaroo? Behav Ecol Sociobiol. 2008;62:757-67.

Pearce-Higgins JW, Brown DJ, Douglas DJT, Alves JA, Bellio M, Bocher P, et al. A global threats overview for Numeniini populations: synthesising expert knowledge for a group of declining migratory birds. Bird Conserv Int. 2017;27:6-34

Pearse AT, Krapu GL, Brandt DA. Sandhill crane roost selection, human disturbance, and forage resources. J Wildl Manage. 2017;81:477-86.

Pfister C, Harrington BA, Lavine M. The impact of human disturbance on shorebirds at a migration staging area. Biol Conserv. 1992;60:115-26.

Piersma T. Eastern Curlews Numenius madagascariensis feeding on Macrophthalrnus and other Ocypodid crabs in the Nakdong Estuary, South Korea. Emu. 1985:86:155-60.

Piersma T. Using the power of comparison to explain habitat use and migration strategies of shorebirds worldwide. J Ornithol. 2007;148(Suppl 1):S45-59.

Rieucau G, Martin JGA. Many eyes or many ewes: vigilance tactics in female bighorn sheep Ovis canadensis vary according to reproductive status. Oikos. 2008;117:501-6.

Schwemmer P, Enners L, Garthe S. Migration routes of Eurasian Curlews (Numenius arquata) resting in the eastern Wadden Sea based on GPS telemetry. J Ornithol. 2016;157:901-5.

Si YL, Xu YJ, Xu F, Li XY, Zhang WY, Wielstra B, et al. Spring migration patterns, habitat use, and stopover site protection status for two declining waterfowl species wintering in China as revealed by satellite tracking. Ecol Evol. 2018;8:6280-9.

Stevens M, Searle WTL, Seymour JE, Marshall KLA, Ruxton GD. Motion dazzle and camouflage as distinct anti-predator defenses. BMC Biol. 2011;9:81.

Studds CE, Kendall BE, Murray NJ, Wilson HB, Rogers DI, Clemens RS, et al. Rapid population decline in migratory shorebirds relying on Yellow Sea tidal mudflats as stopover sites. Nat Commun. 2017:8:14895.

Tian YL, Luo L, Mao D, Wang ZM, Li L, Liang JP. Using Landsat images to quantify different human threats to the Shuangtai Estuary Ramsar site, China. Ocean Coast Manage. 2017;135:56-64.

Treves A. Theory and method in studies of vigilance and aggregation. Anim Behav. 2000;60:711-22.

Ueta M, Antonov A, Artukhin Y, Parilov M. Migration routes of Eastern Curlews tracked from far east Russia. Emu. 2002;102:345-8.

Wang Z, Li ZQ, Beauchamp G, Jiang ZG. Flock size and human disturbance affect vigilance of endangered red-crowned cranes (Grus japonensis). Biol Conserv. 2011;144:101-5.

Wang XD, Kuang FL, Tan K, Ma ZJ. Population trends, threats, and conservation recommendations for waterbirds in China. Avian Res. 2018;9:14.

Xing YQ, Xing JW. Some taxonomy errors in studies on China Suaeda. Marine Sci. 2019:43:97-102 (in Chinese).

Zhang AG, Yuan XT, Yang XL, Shao SL, Li J, Ding DW. Temporal and spatial distributions of intertidal macrobenthos in the sand flats of the Shuangtaizi Estuary, Bohai Sea in China. Acta Ecol Sin. 2016;36:172-9.

Zhang J, Bai Y, Huang ZQ, Zhang ZZ, Li DL. Community composition and behavioral differences of migrating shorebirds between two habitats within a Suaeda salsa saltmarsh-mudflat wetland mosaics. Biodivers Sci. 2021:29:351-60 (in Chinese)

Zhao MJ, Christie M, Coleman J, Hassell C, Gosbell K, Lisovski S, et al. Time versus energy minimization migration strategy varies with body size and season in long-distance migratory shorebirds. Mov Ecol. 2017;5:23.

Zuur AF, leno EN, Elphick CS. A protocol for data exploration to avoid common statistical problems. Meth Ecol Evol. 2010;1:3-14. 